\title{
Personality traits in patients with cluster headache: a comparison with migraine patients
}

\author{
I. Muñoz ${ }^{1}$, M. S. Hernández' , S. Santos ${ }^{2}$, C. Jurado ${ }^{3}$, L. Ruiz ${ }^{4}$, E. Toribio ${ }^{4}$, E. M. Sotelo ${ }^{1}$, A. L. Guerrero ${ }^{5 *}$, V. Molina ${ }^{1}$, \\ F. Uribe ${ }^{1}$ and M. L. Cuadrado ${ }^{6}$
}

\begin{abstract}
Background: Cluster headache $(\mathrm{CH})$ has been associated with certain personality traits and lifestyle features, but there are few studies assessing personality profiles in $\mathrm{CH}$. We aimed to analyze personality traits in patients with $\mathrm{CH}$, and to compare them with those found in migraine.

Methods: We included all consecutive patients with $\mathrm{CH}$ attending 5 outpatient offices between January and December 2013. Personality traits were evaluated using the Salamanca screening test, a validated inventory assessing 11 personality traits grouped in 3 clusters. We analyzed the test results in this population, and compared them with those of a migraine population previously assessed with the same test.

Results: Eighty patients with $\mathrm{CH}$ (75 men, 5 women; mean age, $43.2 \pm 9.9$ years) were recruited. The reference population consisted of 164 migraine patients (30 men, 134 women; mean age $36.4 \pm 12.7$ years). In CH patients, the most frequent personality traits were anancastic (52.5\%), anxious (47.5\%), histrionic (45\%), schizoid (42.5\%), impulsive (32.5\%) and paranoid (30\%). When compared to migraine patients, paranoid ( $p<0.001 ; x 2$ test), and schizoid traits ( $p=0.007 ; \times 2$ test) were significantly more prevalent in $\mathrm{CH}$ patients. In logistic regression analysis the paranoid trait was significantly associated with $\mathrm{CH}$ ( $p=0.001$; OR: 3.27, $95 \% \mathrm{Cl}[1.66-6.43]$ ).

Conclusion: According to the Salamanca screening test, personality traits included in cluster A (odd or eccentric disorders) are more prevalent in $\mathrm{CH}$ patients than in a population of migraineurs. Larger studies are needed to determine whether certain personality traits are related to $\mathrm{CH}$.
\end{abstract}

Keywords: Cluster headache, Eccentric disorders, Migraine, Paranoid personality, Personality traits, Salamanca test, Schizoid personality

\section{Background}

Trigeminal autonomic cephalalgias (TAC) are a group of primary headache disorders that share the clinical features of unilateral headache, and often prominent cranial autonomic features ipsilateral to the headache [1]. Cluster headache $(\mathrm{CH})$ is the most common form of TAC and one of the most severe forms of primary headache [2-4]. According to the International Classification of Headache Disorders, third edition, beta version (ICHD-3, beta) [5], $\mathrm{CH}$ is characterized by a severe or very severe unilateral

\footnotetext{
* Correspondence: gueneurol@gmail.com

${ }^{5}$ Neurology Department, Hospital Clínico Universitario, Avda. Ramón y Cajal

3, 47005 Valladolid, Spain

Full list of author information is available at the end of the article
}

head pain lasting from 15 to $180 \mathrm{~min}$ and occurring from once every other day to eight times a day, accompanied by ipsilateral autonomic symptoms and/or restlessness or agitation. $\mathrm{CH}$ attacks commonly have a striking circadian rhythm, with the attacks occurring at the same time each day, often in the afternoon or evening and during the night. In addition, episodic $\mathrm{CH}$ tends to have a circannual rhythm, with the active periods recurring at the same time of the year. A minority of patients have chronic $\mathrm{CH}$, with the attacks occurring for more than one year without remission, or with remissions lasting less than one month.

Most patients with $\mathrm{CH}$ are men (3:1). $\mathrm{CH}$ leads to significant consequences on patients' professional and social relationships and quality of life, along with a high use of

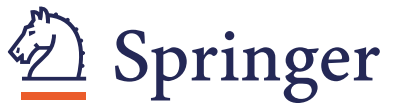

(c) 2016 Muñoz et al. Open Access This article is distributed under the terms of the Creative Commons Attribution 4.0 International License (http://creativecommons.org/licenses/by/4.0/), which permits unrestricted use, distribution, and reproduction in any medium, provided you give appropriate credit to the original author(s) and the source, provide a link to the Creative Commons license, and indicate if changes were made. 
health-care resources [6]. Psychiatric comorbidity in migraine is common and is increasingly being well documented, especially as it relates to major depressive disorder and the spectrum of anxiety disorders [7]. Contrarily to migraine, psychiatric comorbidity of $\mathrm{CH}$ patients has not been broadly assessed apart from few case series [8]. $\mathrm{CH}$ has been associated with anxiety disorders [9-11] and, mainly, depression [12]. In a large chronic cluster population from France, Donnet et al. noticed depression in $43 \%$ [13]. CH has been nicknamed the suicide headache. Rozen et al. looked at the rate of suicidal ideations or true suicide attempts in a large $\mathrm{CH}$ population in USA. They found that an alarming $55 \%$ of the survey responders stated they have had thoughts about suicide, and a $2 \%$ have actually tried to commit suicide [14].

Personality traits might affect disability, resource utilization or adherence to therapies in headache patients. Previous studies have reported that levels of emotional functioning and perception of pain, independent of level of pain at baseline, were predictive of frequency, intensity, and duration of headaches [15]. Patients with headache and premorbid personality with important neurotic characteristics, understood as a personality with significant emotional instability and high levels of anxiety and worry, often have a bad pain management. This might affect the effectiveness of the usual therapies and therefore influence the prognosis of headache, for example with a transformation to a chronic form. The obsessive-compulsive personality trait has been the most frequently related $[16,17]$.

We aimed at analyzing personality traits in a population of $\mathrm{CH}$ patients using a validated screening test, and to compare them with those found in a migraine population.

\section{Methods}

We assessed all consecutive patients with $\mathrm{CH}$ attending five headache outpatient offices from January 2013 to December 2013. CH was diagnosed according to both the second and third editions of the ICHD criteria $[5,18]$. We obtained a complete history from each patient recording the demographic and clinical data systematically. We excluded patients with other headache diagnoses (including migraine), as well as patients with a medical or psychiatric disorder, not included within mood disorders or anxiety, or intellectual deficit that would limit their ability to understand or answer the questions of the questionnaires are included. The evaluation of depressive and anxiety symptoms was performed with the Hospital Anxiety and Depression Scale developed by Zigmond and Snaith [19]. It is a self-assessment scale, consisting on 14 items grouped into two subscales: anxiety and depression. The cutoff established for each of the subscales is 10 . The HADS is especially useful for headache sufferers, since none of the 14 items refers to somatic symptoms, eliminating the risk of an overestimation of psychopathology derived from the interpretation of physical symptoms associated with headache secondary to anxiety or depression.

The study was approved by the Ethics Committee of the University Hospital of Valladolid, and all patients gave informed consent before participation.

We evaluated personality traits using the original Spanish version of the Salamanca screening test, a short, validated, and easy-to-interpret test, suitable for use in a neurology outpatient office [20]. The Salamanca test was designed to screen the eleven specific personality traits by using a total of 22 questions, two for each trait. There are four answers for each question. To screen the traits, for each answer a maximum of three points can be given. Thus, for each trait a scale from 0 to 6 indicates the degree of matching that specific personality trait. One of the main qualities of this test is its high sensitivity which leads to an early detection of personality features which can be sufficiently subtle so as not to be readily evident. Table 1 shows the English certified translation of the Salamanca test.

Personality traits assessed by the Salamanca test were grouped into three clusters as shown in Table 2. Cluster A included paranoid, schizoid and schizotypal traits; Cluster B comprised antisocial, narcissistic, histrionic, and emotional instability disorders subtypes limit and impulsive, while Cluster C included dependent, anancastic and anxious traits [21]. This test was previously administered to migraine patients attending the same outpatient clinics and coming from the same geographical areas [22].

Statistical analysis was conducted with the SPSS statistical package (version 20.0 Inc., Chicago, IL, USA). Univariate association between personality traits and type of headache ( $\mathrm{CH}$ or migraine) was assessed with the $\chi 2$ test. Personality traits associated with any type of headache $(p<0.2$ in univariate analysis) were subsequently included in a logistic regression analysis. As gender distribution was markedly different between $\mathrm{CH}$ and migraine patients, in order to exclude any influence of gender on personality traits, gender was included in a second regression analysis in each of the populations ( $\mathrm{CH}$ or migraine). All models were constructed using backward and forward stepwise variable selection. A $p$-value of $<0.05$ was considered significant.

\section{Results}

We included 80 patients with $\mathrm{CH}$ (5 female, 75 male). Mean age at inclusion was $43.2 \pm 9.9$ years (range: $23-64$ ) and mean age at onset was $31.3 \pm 11.8$ (range: 10-57). At the time of assessment, 67 patients $(83.8 \%)$ had episodic headache, and 13 patients (16.2\%) had chronic $\mathrm{CH}$. In the migraine group there were 164 patients (134 female, 30 male), with mean age at inclusion of $36.4 \pm 12.7$ years (range: 10-78) and mean age at onset of $19.5 \pm 9.2$ (range: 
Table 1 English translation of Salamanca Test

1. I am reluctant to confide
in others
2. I would like to give
others what they deserve
3. I prefer solitary activities
4. I prefer being alone
5. Do people think you are
strange or eccentric?
6. I am more in touch with the
paranormal than most people
7. I am too emotional

8. I care a lot about my image

9. I do illegal things

10. I have little respect for the rights of others

11. I am special and deserve to be recognized for it

12. Many people are envious of me.

13. My emotions are like a roller coaster

14. I am impulsive

15. I frequently wonder what my purpose in life is

16. I am easily bored or have feelings of emptiness

17. Do people think you are too perfectionist, obstinate or rigid?

18. I am meticulous, thorough and too much of a hard-worker.

19. I need to feel cared for and protected.

20. I find it hard to make my own decisions.

21. I am a nervous person.

22. I am very afraid of being ridiculous.
$T$ sometimes frequently always $F$

$\begin{array}{lll}1 & 2 & 3\end{array}$

$T$ sometimes frequently always $F$

$\begin{array}{lll}1 & 2 & 3\end{array}$

$\mathrm{T}$ sometimes frequently always $\mathrm{F}$

$$
\begin{array}{lll}
1 & 2 & 3
\end{array}
$$

$T$ sometimes frequently always $F$ $\begin{array}{lll}1 & 2 & 3\end{array}$

$\mathrm{T}$ sometimes frequently always $\mathrm{F}$

$\begin{array}{lll}1 & 2 & 3\end{array}$

$T$ sometimes frequently always $\mathrm{F}$

$\begin{array}{lll}1 & 2 & 3\end{array}$

$\mathrm{T}$ sometimes frequently always $\mathrm{F}$ $\begin{array}{lll}1 & 2 & 3\end{array}$

$\mathrm{T}$ sometimes frequently always $\mathrm{F}$

$\begin{array}{lll}1 & 2 & 3\end{array}$

$\mathrm{T}$ sometimes frequently always $\mathrm{F}$

$\begin{array}{lll}1 & 2 & 3\end{array}$

$\mathrm{T}$ sometimes frequently always $\mathrm{F}$

$\begin{array}{lll}1 & 2 & 3\end{array}$

$\mathrm{T}$ sometimes frequently always $\mathrm{F}$

$\begin{array}{lll}1 & 2 & 3\end{array}$

$\mathrm{T}$ sometimes frequently always $\mathrm{F}$

$\begin{array}{lll}1 & 2 & 3\end{array}$

$\mathrm{T}$ sometimes frequently always $\mathrm{F}$ $\begin{array}{lll}1 & 2 & 3\end{array}$

$\mathrm{T}$ sometimes frequently always $\mathrm{F}$

$\begin{array}{lll}1 & 2 & 3\end{array}$

$\mathrm{T}$ sometimes frequently always $\mathrm{F}$ $\begin{array}{lll}1 & 2 & 3\end{array}$

$\mathrm{T}$ sometimes frequently always $\mathrm{F}$

$\begin{array}{lll}1 & 2 & 3\end{array}$

$\mathrm{T}$ sometimes frequently always $\mathrm{F}$

$\begin{array}{lll}1 & 2 & 3\end{array}$

$T$ sometimes frequently always $F$

$\begin{array}{lll}1 & 2 & 3\end{array}$

$\mathrm{T}$ sometimes frequently always $\mathrm{F}$

$\begin{array}{lll}1 & 2 & 3\end{array}$

$\mathrm{T}$ sometimes frequently always $\mathrm{F}$

$\begin{array}{lll}1 & 2 & 3\end{array}$

$\mathrm{T}$ sometimes frequently always $\mathrm{F}$

$\begin{array}{lll}1 & 2 & 3\end{array}$

$T$ sometimes frequently always $\mathrm{F}$ $\begin{array}{lll}1 & 2 & 3\end{array}$
Table 2 Personality traits assessed by Salamanca Test grouped into 3 Clusters

\begin{tabular}{lll}
\hline Cluster A & PAR & Paranoid (items 1 and 2) \\
& SCHZD & Schizoid (items 3 and 4) \\
& SCHT & Schizotypal (items 5 and 6) \\
Cluster B & HIST & Histrionic (items 7 and 8) \\
& ANT & Antisocial (items 9 and 10) \\
& NAR & Narcissistic (items 11 and 12) \\
& EU IMP & Emotionally unstable disorders \\
& EU LIM & Empulsife type (items 13 and 14) \\
& Emotionally unstable disorders \\
& BNAN & Anancastic personality disorder. \\
& DEP & (items 17 and 18) \\
& Dependent (items 19 and 20) \\
& AnX & Anxious personality disorder \\
& (items 21 and 22) \\
\hline
\end{tabular}

5-50). As expected, most patients with $\mathrm{CH}$ were male, in contrast with female migraine patients.

In the $\mathrm{CH}$ group, the most frequent personality traits were anancastic (52.5\%), anxious (47.5\%), histrionic (45\%), schizoid (42.5\%), impulsive (32.5\%) and paranoid (30\%). Most patients shared several personality traits, especially those belonging to cluster A.

A comparison between the distribution of personality traits in $\mathrm{CH}$ patients and migraine patients is shown in Table 3. Only two of the 11 personality traits assessed (dependent and anxious) were more frequent in migraine patients.

In the first logistic regression analysis only the paranoid trait was significantly associated with $\mathrm{CH}(p=$ 0.001; OR: 3.27, 95 \% CI [1.66-6.43]). No relationship

Table 3 Comparison between personality traits in Cluster headache patients and migraine patients

\begin{tabular}{llll}
\hline Personality traits & $\begin{array}{l}\text { Cluster headache } \\
\text { patients (n: 80) }\end{array}$ & $\begin{array}{l}\text { Migraine patients } \\
\text { (n: 164) }\end{array}$ & $\begin{array}{l}\text { *P value } \\
\text { (x2 test) }\end{array}$ \\
\hline Paranoid (\%) & $30 \%$ & $11.6 \%$ & $<0.001$ \\
Schizoid (\%) & $42.5 \%$ & $25.6 \%$ & 0.007 \\
Schizotypal (\%) & $10 \%$ & $5.5 \%$ & 0.19 \\
Histrionic (\%) & $45 \%$ & $40.9 \%$ & 0.53 \\
Antisocial (\%) & $2.5 \%$ & $0 \%$ & 0.10 \\
Narcisistic (\%) & $6.3 \%$ & $4.9 \%$ & 0.65 \\
EIDSI (\%) & $32.5 \%$ & $23.8 \%$ & 0.14 \\
EIDSL (\%) & $18.8 \%$ & $15.9 \%$ & 0.57 \\
Anancastic (\%) & $52.5 \%$ & $44.5 \%$ & 0.24 \\
Dependent (\%) & $27.5 \%$ & $32.9 \%$ & 0.39 \\
Anxious (\%) & $47.5 \%$ & $53.7 \%$ & 0.36 \\
\hline
\end{tabular}

EIDSI Emotional instability disorder subtype impulsive

EIDSL Emotional instability disorder subtype limit 
between gender and personality traits was found in the second regression analysis within the $\mathrm{CH}$ or the migraine groups. Patients with episodic and chronic $\mathrm{CH}$ did not show different personality profiles (data not shown).

\section{Discussion}

Patients with $\mathrm{CH}$ seem to be more vulnerable to diverse psychiatric comorbidities [8]. Depression is the best acknowledged psychiatric comorbidity in this headache; a recent study concluded that $\mathrm{CH}$ patients were 5.6 times more likely to develop depression than the control population [23]. Several authors have also tried to describe the mental profile of these patients [24-26]. A particular personality profile has been proposed for $\mathrm{CH}$ patients, which would be characterized by ambition, dependency and an inability to reveal their feelings [27]. They were even described as "mice living inside lions" [28]. Personality studies have shown that these patients are more prone to anxiety, hypochondriasis and hysteria [24, 29-31]. CH patients are less successfully socially integrated, and have a more hostile attitude towards others [24]. However, some authors maintained that data used for defining personality profiles just reflected coping resources of patients against pain [32]. Anyway, it has not been possible to define rigorously a personality profile for $\mathrm{CH}$ patients [26, 30, 33-35].

In contrast, relationships between migraine and psychiatric comorbidities have been more extensively analyzed [36-38], especially regarding the axis I of the Diagnostic and Statistical Manual of Mental Disorders, 4th Edition, Text Revision (DSM-IV-TR), [39, 40]. Concerning personality traits, axis II of DSM-IV-TR, this difference is even more remarkable $[18,41]$.

A personality trait is a stable and pervasive pattern of interpreting, perceiving, thinking about, and relating to one's environment, as well as to oneself. It is stable over time. A personality trait affects individual's life and cannot be explained by substance abuse, other mental disorder or medical conditions. The personality traits are grouped into three clusters: A, B and C. Cluster A comprises odd or eccentric traits, cluster B dramatic or emotional disorders traits and cluster $\mathrm{C}$ consists of anxious or fearful traits.

According to our results obtained using the Salamanca screening test, it seems that some personality traits belonging to Cluster A are quite common among $\mathrm{CH}$ patients, while personality traits included in Cluster $\mathrm{C}$ are apparently more frequent among migraine patients. Cluster $C$ reflects an anxious and stress reactive personality while cluster $\mathrm{A}$ reveals a rigid way of thinking and feeling relating to the others. This means that most of the patients diagnosed with $\mathrm{CH}$ exhibit a paranoid-schizoid position. This position may influence their response to pain and result in an inadequate coping strategy. These results are similar to those obtained by other authors with the Minnesota Multiphasic Personality Inventory (MMPI) questionnaire, in which high paranoia and hypochondria levels ocurred among $\mathrm{CH}$ patients [42], but differed from others with comparable MMPI scores in $\mathrm{CH}$ and migraine patients [32, 43-45]. Otherwise, this study provides some evidence that psychiatric comorbidity may be related with primary headache itself, as already pointed out by Robbins [7].

Different personality profiles might be explained as a response to continued exposure to pain, as it would occur in chronic forms, or to the risk of sudden intense pain, as would happen in episodic pains [46]. We have not found different profiles in chronic or episodic $\mathrm{CH}$, though the number of chronic forms in our series is too small to reach a conclusion. However headache chronification has been related with psychiatric comorbidity, due the significant role it might play in the way of perceive pain, cope with it and maintain a normal lifestyle. We could expect high scores in personality traits of chronic $\mathrm{CH}$ in a bigger series.

There are several major limitations of this survey study, the main one being that we do not have a matched healthy control population. As gender distributions between $\mathrm{CH}$ and migraine populations are quite different, they might mask any comparison concerning other variables. Yet, we have not found a significant influence of gender on personality traits in each population. Another problem was that the use of the Salamanca screening test helped us to evaluate personality traits in a neurology outpatient office but is considered a somewhat overinclusive instrument in "making diagnosis" [20]. Finally, the cross-sectional design of the study does not permit to reveal any casual relationship. Larger studies are needed to solve these limitations and to confirm whether personality traits are directly related to $\mathrm{CH}$ and if they differ from those related to other primary headaches.

\section{Conclusion}

According to our results, personality pattern is different among migraine and Cluster Headache Patients. So, psychological profile may somehow be marked by the primary headache. This study would reflect a paranoidschizoid personality among $\mathrm{CH}$ patients that might influence the response of these patients to therapy, or even their therapeutic alliance with neurologists. The personality pattern showed in our data could be related to a difficult coping with changes and pain.

\section{Consent}

Consent to publish has been obtained from the participants. 


\section{Competing interests}

The authors declare that they have no competing interests.

\section{Authors' contributions}

Conception and Design: IM, VM, ALG, MLC. Acquisition of Data: IM, SS, CJ, LR, ET, MLC. Analysis of Data: IM, MSH, EMS, VM, FU. Drafting the manuscript: IM, VM, ALG, MLC. Revising manuscript: MSH, SS, CJ, LR, ET, EMS, FU. All authors read and approved the final manuscript.

\section{Acknowledgement}

Partially presented as an Oral Communication at the XXIII Meeting of the European Neurological Society. Barcelona, June 2013.

\section{Author details}

${ }^{1}$ Psychiatry Department Hospital Clínico Universitario, Valladolid, Spain. ${ }^{2}$ Neurology Department, Hospital Clínico Universitario Lozano Blesa, Zaragoza, Spain. ${ }^{3}$ Neurology Department, Hospital Universitario Reina Sofía, Córdoba, Spain. ${ }^{4}$ Neurology Department, Hospital Universitario del Henares, Coslada, Madrid, Spain. ${ }^{5}$ Neurology Department, Hospital Clínico Universitario, Avda. Ramón y Cajal 3, 47005 Valladolid, Spain. ${ }^{6}$ Neurology Department. Hospital Clínico San Carlos, Universidad Complutense, Madrid, Spain.

\section{Received: 13 January 2016 Accepted: 9 March 2016}

\section{Published online: 15 March 2016}

\section{References}

1. Costa A, Antonaci F, Ramusino MC, Nappi C (2015) The neuropharmacology of Cluster Headache and other Trigeminal Autonomic Cephalalgias. Curr Neuropharmacol 13(3):304-23

2. Fischera M, Marziniak M, Gralow I, Evers S (2008) The incidence and prevalence of cluster headache: A meta-analysis of population-based studies. Cephalalgia 28:614-618

3. Larner AJ (2008) Trigeminal Autonomic cephalalgias: Frequency in a general neurology clinic setting. J Headache Pain 9:325-326

4. Jensen R, Lyngberg A, Jensen R (2007) Burden of cluster headache. Cephalalgia 27:535-541

5. Headache Classification Subcommittee of the International Headache Society (2013) The international classification of headache disorders: 3 rd edition (beta version). Cephalalgia 33:629-808

6. D'Amico D, Rigamonti A, Solari A et al (2002) Health-related quality of life in patients with cluster headache during active periods. Cephalalgia 22:818-821

7. Jelinski SE, Magnusson JE, Becker WJ (2007) Factors associated with depression in patients referred to headache specialists. Neurology 68:489-495

8. Gesztelyi G, Bereczki D (2005) Disability is the major determinant of the severity of depressive symptoms in primary headaches but not in low back pain. Cephalalgia 2:598-604

9. Robbins MS, Bronheim R, Lipton RB et al (2012) Depression and anxiety in episodic and chronic cluster headache: a pilot study. Headache 52:600-11

10. Jürgens TP, Gaul C, Lindwurm A et al (2011) Impairment in episodic and chronic cluster headache. Cephalalgia 31:671-682

11. Jorge RE, Leston JE, Arndt S, Robinson RG (1999) Cluster headaches: Association with anxiety disorders and memory deficits. Neurology 53:543-547

12. Seifert CL, Valet M, Pfaffenrath $V$ et al (2011) Neurometabolic correlates of depression and disability in episodic cluster headache. J Neurol 258:123-131

13. Donnet A, Lanteri-Minet M, Guegan-Massardier E et al (2007) Chronic cluster headache: A french clinical descriptive study. J Neurol Neurosurg Psychiatry 78:1354-1358

14. Rozen TD, Fishman BA (2012) Cluster headache in the United States of America: Demographics, Clinical Characteristics, Triggers, Suicidality, and Personal Burden. Headache 52:99-113

15. Pompili M, Gianluca S, Di Cosimo D et al (2010) Psychiatric comorbidity and suicide risk in patients with chronic migraine. Neuropsychiatr Dis Treat 6:81-91

16. Curone M, D'Amico D, Bussone G (2012) Obsessive-compulsive aspects as predictors of poor response to treatments in patients with chronic migraine and medication overuse. Neurol Sci 33(Suppl1):S211-S213

17. Bigal ME, Sheftell FD, Rapaport AM, Tepper SJ, Weeks R, Baskin SM (2003) MMPI personality profiles in patients with primary chronic headache: $A$ case-control study. Neurol Sci 24:103-110
18. Headache Classification subcommittee of the International Headache Society (2004) The international classification of headache disorders second edition. Cephalalgia 24(Suppl 1):S9-160

19. Zigmond AS, Snaith RP (1983) The hospital anxiety and depression scale. Acta Psychiatr Scand 67:361-370

20. Caldero-Alonso A (2009) Estudio de los resultados obtenidos en el Cuestionario Salamanca en población normal. Universidad de Salamanca, Salamanca

21. López-Ibor Aliño JJ, Valdés-Miyar M (2002) Manual diagnóstico y estadístico de los trastornos mentales. Masson, Barcelona

22. Muñoz I, Toribio-Diaz ME, Carod-Artal FJ et al (2013) Personality traits in patients with migraine: a multi-centre study using the Salamanca screening questionnaire. Rev Neurol 57(12):529-34

23. Liang JF, Chen YT, Fuh JL, Li SY, Liu CJ, Chen TJ (2013) Cluster headache is associated with an increased risk of depression: A nationwide populationbased cohort study. Cephalalgia 33(3):182-9

24. Kudrow L (1974) Physical and personality characteristics in cluster headache. Headache 13:197-202

25. Italian Cooperative Study Group on the Epidemiology of Cluster Headache (ICECH) (2000) Case-control study on the edpidemiology of cluster headache: anthropometric data and personality profile. Funct Neurol 15(4):215-23

26. Levi R, Edman GV, Ekbom K, Waldenlind E (2005) Episodic cluster headache I: personality and some neuropsychological characteristics in male patients. Headache J Head Face Pain 32(3):119-125

27. Graham JR (1975) Some clinical and theoretical aspects of cluster headache In: Saxena PR (ed) Migraine and related Headaches. Erasmus Universiteit, Roterdam, pp 27-40

28. Graham JR (1972) Cluster headache. Headache 11:175-85

29. Rogado AZ, Harrison RH, Graham JR (1974) Personality profiles in cluster headache, migraine and normal controls. Arch Neurobiol 37:227-241

30. Evers S (2005) Cognitive processing in cluster headache. Curr Pain Headache Rep 9:109-112

31. Steinhilber RM, Pearson JS, Rushton JG (1960) Some psychological considerations of histaminic cephalalgia. Mayo Clin Proc 35:691-699

32. Robinson ME, Geisser ME, Dieter JN, Swerdlow B (1991) The relationship between MMPI cluster membership and diagnostic category in headache patients. Headache 31:111-115

33. Pfaffenrath V, Hummelsberg J, Pöllmann W, Kaube H, Rath M (1991) MMPI personality profiles in patients with primary headache syndromes. Cephalalgia 11:263-268

34. Mathew NT (1992) Cluster headache. Neurology suppl. 2(3):22-31

35. Zwart JA, Ellertsen B, Bovim G (1996) Psychosocial factors and MMPI-2 patterns in migraine, cluster headache. New Trends Exp Clin Psychiatry 12(3):167-174

36. Jette N, Patten S, Williams J, Becker W, Wiebe S (2008) Comorbidity of Migraine and Psychiatric Disorders. A National Population-Based Study. Headache 48:501-516

37. Hamelsky SW, Lipton RB (2006) Psychiatric comorbidity of migraine. Headache 46:1327-1333

38. Antonaci F, Nappi G, Galli F, Manzoni GC, Calabresi P, Costa A (2011) Migraine and psychiatric comorbidity: a review of clinical findings. J Head Pain 12:115-25

39. Lake III AE, Rains JC, Penzien DB, Lipchick GL (2005) Headache and psichiatric comorbidity: Historical context, clinical implications, and research relevance. Headache 45:493-506

40. Radat F, Swendsen J (2004) Psychiatric comorbidity in migraine: a review. Cephalalgia 25:165-178

41. Luconi R, Bartolina M, Taffi R, Vignin A, Mazzanti L, Provinciali L et al (2007) Prognostic Signifiance of personality profiles in patients with chronic migraine. Headache 47:1118-1124

42. Cupini LM, De Murtas M, Costa C, Mancini M, Eusebi P, Sarchielli P et al (2009) Obsessive-compulsive disorder and migraine with medication-overuse headache. Headache 49:1005-1013

43. Kudrow LO, Suktus BJ (1979) MMPI pattern specificity in primary headache disorders. Headache 19:18-24

44. Cuypers J, Altenkirch H, Bunge S (1981) Personality profiles in cluster headache and migraine. Headache 21:21-24

45. Watson D (1982) Neurotic tendencies among chronic pain patients: an MMPI item analysis. Pain 14:365-385

46. De Domini P, Del Bene E, Gori-Savellini S, Manzoni GC, Martucci N, Nappi G et al (1983) Personality patterns of headache sufferers. Cephalalgia 3(Suppl 1):195-214 